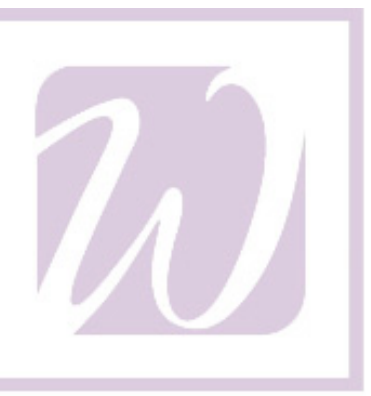

UW-WHITEWATER

\title{
Modeling the Time to an Initial Public Offering: When does the Fruit Ripen?
}

\author{
By
}

Yamin S. Ahmad and Russell Kashian

Working Paper 08 - 01

University of Wisconsin - Whitewater

Department of Economics

$4^{\text {th }}$ Floor Carlson Hall

800 W. Main Street

Whitewater, WI 53538

Tel: (262) $472-1361$ 


\title{
Modeling the Time to an Initial Public Offering: When does the Fruit Ripen?
}

\author{
Yamin Ahmad ${ }^{\dagger}$ and Russ Kashian \\ University of Wisconsin - Whitewater
}

\begin{abstract}
This paper investigates the characteristics possessed by credit unions who have converted to mutual savings institutions, which might lead them to demutualize and become publicly traded banks. We adopt a duration model framework to examine these characteristics. Our key findings are as follows. First, we find evidence of positive duration dependence in the data we examine. Second, we find that the hazard of an IPO issue increases in two waves. The first occurs between three and a half to four years reflecting the increased transition intensity for those who wish to demutualize early. However, the majority of the institutions in our sample do so by approximately eight years after conversion, and this is where the second spike in the hazard occurs. Finally, upon estimating the model with Cox's (1975) semi-parametric partial likelihood approach, we find the probability that a converted institution will issue an IPO is influenced to a large extent by various measures that capture asset quality, in particular through measures that are equity driven. However, contrary to what one might expect, we find that total assets do not appear to influence the hazard rate.
\end{abstract}

JEL Classification: C41, G20, G21, L33

Keywords: Credit Unions, Demutualization, Hazard analysis, IPO

Initial Version: May $1^{\text {st }} 2007$

Current Version: April 28 2008

\footnotetext{
† Corresponding Author: Department of Economics, University of Wisconsin Whitewater, 800 W Main Street, Whitewater, WI 53190 Email: ahmady@uww.edu, Homepage: http://facstaff.uww.edu/ahmady/ Tel: (262) 4725576

\# Department of Economics, University of Wisconsin Whitewater, 800 W Main Street, Whitewater, WI 53190

Email: kashianr@uww.edu, Tel: (262) 4725584
} 


\section{Introduction}

The financial sector is currently witnessing a focused, but unique transformation. In this transformation, two events occur, often within a limited time frame. The first movement is the conversion of credit unions to mutual savings banks. Following the passage of the Credit Union Membership Act of 1998, the conversion of credit unions to mutual savings banks became easier. The second movement is the demutualization of these recently converted institutions into publicly traded banks. While there is considerable literature regarding the conversion of mutual savings banks to publicly traded banks, this paper seeks to connect the literature regarding the conversion of credit unions and the conversion of mutual savings banks. It uses a hazard model to identify some of the characteristics that might lead the converted institution to issue an initial public offering (IPO).

Over the past ten years, over 20 credit unions in the U.S. have converted to mutual savings banks. The majority of these institutions subsequently converted to stock-owned institutions. This activity, while very limited in terms of number of institutions, is hotly debated. Opponents of this activity say that in almost every case this process is motivated by insiders attempting to garner an economic transfer of wealth. Given the literature regarding the under-pricing of mutual conversions, insiders can anticipate a windfall as directors and top managers of the erstwhile credit union take advantage of the initial offering of stock.

This paper pulls together the strands of literature regarding the transformation from credit union to mutual banks to stock owned banks. These three forms of ownership are unique in their structure. Credit unions differ from mutual savings banks in several ways. First, CUs 
operate on a "one person one vote", principle in which each member has an equal vote in electing the board of directors. Mutual savings banks use weighted voting where depositors exercise a number of votes proportional to the dollar amount of deposits they hold at the bank. Credit union membership requires a share savings account, while mutual savings banks customers can either participate as savers, borrowers, or both. Stock ownership differs strongly from these two ownership forms. In a stock owned bank, investors must purchase stock (their ownership is not a function of participation in the operations of the institution). In addition, they hold a divisible claim on the assets of the institution.

The conversion of credit unions to mutual status is a development that has the attention of both researchers and the public. One reason is the size of the industry in terms of institutions. There are currently over 8,000 credit unions in the United States. This is more than ten times the number of remaining mutual thrifts. Another reason is the timing of this development. While this effort by credit unions to convert into mutuals is picking up, it is occurring as the effort to demutualize the historic mutuals is past its zenith (Kashian and Monaco, 2003). This dichotomy (the intriguing development of conflicting conversions) calls into question the benefit of mutualization in an era of demutualization.

The subsequent demutualization is an attempt to derive value from the non-specificity in the ownership of mutual savings banks (thrifts). As a result, demutualization has been a popular movement, as evidenced by the hundreds of demutualizations conducted over the past thirty years. When a mutual converts to a publicly traded stock corporation, it once again transforms into a unique form of ownership. The nature of the mutual allows depositors to own the firm through participation in the ordinary business of the thrift; the stock form of 
ownership allows the investors to own the firm through the purchase of equity. Ultimately, demutualization changes the economic makeup of ownership.

It is within this backdrop that we investigate the pattern of duration dependence that exists when converted credit unions demutualize and issue an initial public offering. We begin our analysis by estimating the survivor, hazard and integrated hazard functions nonparametrically using Kaplan-Meier product limit estimators. We use these to examine the pattern of duration dependence that exists in the data. We then utilize Cox's (1975) partial likelihood approach to estimate a proportional hazards model with time varying covariates. We examine various factors that contribute towards the observed pattern of duration dependence. We focus on factors that are likely to influence the probability that a mutual savings bank will demutualize due to the wealth motive mentioned above, as well as through a genuine need to raise additional capital.

The remainder of the paper proceeds as follows. The next section places this paper in the context of the relevant literature. Section 3 describes the data, outlines the methodology used to estimate the hazard functions and discusses the results from the nonparametric estimation of the hazard function. Section 4 estimates the data using the Cox (1975) partial likelihood model, and examines the various factors that contribute to an IPO issue. Section 5 concludes.

\section{A Review of the Literature}

There is a narrow history of the differences and evolution of Credit Unions, Mutual Savings

Banks and Publicly Traded Banks. In an effort to weave together the literature, we can 
separate the literature into three strands: the benefits offered by credit unions, the financial incentive for demutualization on insiders, and the arguments for a public offering for thrifts. The first strand often highlights the beneficial differences offered by the credit union movement. Among these articles include (Srinivasan and King, 1998), which focuses on the consumer credit market offered by credit unions.

Feinberg and Rahman (2001) find that there is a competitive interaction between credit unions and banks within a defined market: the greater the presence of credit unions, the lower the interest rates on loans charged by banks. These concepts are highlighted in the literature (Feinberg, 2002, 2003 and 2004; Feinberg and Rahman (2006); Tokle, 2005; Tokle and Tokle, 2000; Hannan, 2002; Focarelli and Panetta, 2003; and Heinrich and Kashian, 2007) which determine that the competitive behavior of credit unions with respect to the interest rate on savings loan products from banks and credit unions. This body of literature confirms that credit unions are a competitive player on the fringe. This competition results in lower loan rates and higher saving rates. While the literature documents an interest rate differential and advantage provided by credit unions, the mutualization of credit unions is a market reality.

Following the passage of the Credit Union Membership Act of 1998, the conversion of credit unions to mutual savings banks (mutualization) became easier. The bridge from mutual-to-stock thrift conversions is relevant to the credit union movement since a high percent of credit unions that convert into mutual thrifts subsequently offer an initial public offering and convert to a stock ownership firm. As a result of the shrinking number of remaining mutuals to the possibility of larger numbers of credit unions converting into 
mutuals, this opportunity has attracted the interest of professionals in the conversion industry (Wilcox, 2006). Over the past ten years, over 20 credit unions in the U.S. have converted to mutual savings banks. Following the pattern of the thrift industry, the majority of these institutions have subsequently converted to stock-owned institutions.

The demutualization process is initiated by insiders. It completes the economic transfer of wealth from credit union members to the mutual to the insiders. This occurs as directors and top managers of the erstwhile credit union take financial advantage of demutualization and the initial offering of stock (Masulis, 1987; Maksimovic and Unal, 1993; Peristiani et al, 1997; Unal, 1997; Jordan, et al, 1998; Kashian and Monaco, 2003; Chaddad and Cook, 2004). Dominating this demutualization literature is the consideration of underpricing. "Underpricing" is often measured as the difference between the IPO price $\left(\mathrm{P}_{\mathrm{o}}\right)$ and closing price on the first day of trading $\left(\mathrm{P}_{1}-\mathrm{P}_{\mathrm{o}}\right) /\left(\mathrm{P}_{\mathrm{o}}\right)$ (Beatty and Richter, 1986). This issue about underpricing in the conversion of mutual thrifts carries a specific suspicion over intentional underpricing which has a fairness implication that runs through the credit union and mutual savings bank industries. This fairness implication implies windfall profits to the few that purchase stock. This possibility also encourages the demutualization process, and it is one of the factors that we consider within this paper. ${ }^{1}$

In an effort to bolster the IPO decision, it is critical to review the judicious reasons to pursue an IPO. Masulis (1987) argues that the primary motive for conversion is to obtain additional

1 A corollary to this idea is considered in related work by Mehran and Peristiani (2007), where the process works in reverse. They use a duration model approach and find that many firms who went private between 1990 and 2004 were young IPO firms who then subsequently reverted back to a more concentrated ownership structure. They attribute it towards an inability to attract a sufficient level of financial interest. However, their findings may have relevance for the credit union industry in the future. 
capital exploit growth opportunities, and in doing so, establishes that industry specific factors play a role. An IPO provides an opportunity for the erstwhile thrift to expand its capital quickly. In addition, there is an efficiency argument which suggests that restrictions on ownership harms a bank's performance (Cole and Mehran, 1998). However, Peristiani and Wizman (1997) caution that there is an agency effect on future profits which exists when firms overcapitalize with an IPO. As a result, it is possible that highly capitalized firms (or firms with limited expansion plans) may consider their need for funds in an inverse relationship to price.

Pagano et al (1998) looks at all firms and industry in an analysis of the various benefit a firm gains by going public. Included within his thesis is the market liquidity it offers the investor. Prior to the IPO, the mutual customer owned an interest in the institution, but lacked a market to trade in that asset. A second consideration would be the capital it offers the institution and the portfolio opportunities that creates. Finally, there exists a belief that the unspecified window of opportunity to convert may not exist in the future.

\section{Data and Nonparametric Estimation of the Hazard Function}

Our analysis begins by examining the pattern of duration dependence that exists in the data. After describing the data, summary statistics that characterizes the data are provided. We then proceed to outline our methodology for estimating the hazard function and reporting the results from the nonparametric estimation. 


\section{Data}

SNL Financial Services provides the data used in this paper. This firm, which specializes in financial institution database assembly, culls data from end of year call reports. In our data, the original credit unions are either acquired by a mutual savings bank or convert to a mutual savings bank. These mutual savings institutions may then proceed to offer an IPO. If a credit union converts and issues an IPO, we refer to the actual IPO issue as an event in what follows. Alternatively, we refer to censored observations as observations where a mutual conversion occurs, but then no subsequent IPO issue is observed by the end of the sample.

Our data is quarterly with twenty three credit unions that are observed from the first quarter of 1997 up until the fourth quarter of 2007. Despite the limited cross sectional observations, we proceed with our analysis since we are creating a baseline study. This paper examines the factors that might lead these institutions to subsequently demutualize and become publicly traded banks. While this baseline study may appear premature, we believe it is critical to provide an insight prior to the total transformation of an industry. There are more than eight thousand credit unions that have the ability to convert to a mutual savings institution. If policy recommendations are to be reviewed, there needs to be an opportunity for these policies to have impact. ${ }^{2}$ Moreover, although the cross sectional dimension of the data is small since this phenomenon of mutual conversion and subsequent demutualization started only relatively recently for credit unions, the time varying covariates in our estimation later in the paper augment the lack of cross sectional observations through the time series dimension.

\footnotetext{
2 To use a farming analogy, when a farmer looks out of the kitchen window and sees a few cows out of the pen, he typically does not wait until all the cows are lose before checking out the gate. He inspects the gate immediately. This study is an economic gate check on the credit union/mutual savings bank industry.
} 
Based on this, our analysis has 412 observation periods. Table 1 reports some summary statistics from the data. Fifteen events occur during these periods, providing an incidence rate of 0.0364 (- the ratio of events to the total number of observed periods). Within the sample, the converted credit unions had asset holdings ranging from approximately $\$ 9$ million to $\$ 1.5$ billion, whilst the ratio of equity to assets ranges from 4.2 percent to 23.23 percent. The converted credit unions that issued an IPO had an equity capital of approximately 9 percent percent of their assets on average, whilst those that maintained mutual status had an equity to asset ratio of approximately 10.5 percent on average. When taking the standard deviation of the equity to asset holdings into account, as a first approximation, the credit unions that issued an IPO do not appear to be significantly different to those that did not issue an IPO within our sample, in terms of their equity to asset ratio.

Table 1 also includes the median values and the ranges of the ratios of net income to total assets, total loans to total assets, along with the number of branches and employees that the converted credit union had. The ratio of net income to total assets reflects the earnings of the credit union, conditioned on the size of the institution (reflected by its asset holdings). This number ranges from approximately -0.2 percent (i.e. those making losses) to approximately 0.8 percent (i.e. those with positive earnings). The ratio of total loans to total assets reflects the extent to which a converted credit union's assets are concentrated in the form of loans. This number varies from 32.47 percent to 95.71 percent. Section 4 examines the effects of some of these characteristics on the hazard function and its impact on the probability that a converted credit union issues an IPO in greater detail. 


\section{Estimation Methodology}

We utilize a hazard model framework so that we may identify some of the characteristics that credit unions possess, which might lead them to convert and then issue an IPO. Unlike the more common discrete outcome models, hazard models explicitly incorporate information about the timing of events, thereby making more efficient use of the data. In employing our estimation and modeling strategy, we have to account for the fact that a (small) number of credit unions are acquired by banks. The remainder of the credit unions in our sample convert to either a mutual savings bank or a savings institution. We treat credit unions that are acquired as censored observations on the date of acquisition. We adopt this approach since we assume that censored observations do not provide any further information about latent IPO issue times beyond what is available in the covariates. In essence, this is because we are unable to observe the final outcome for these institutions whether they issue an IPO or not, and hence cannot assign them a duration value $t$. Including them in the hazard rate calculations would create a downward bias by inflating the survivor function. This approach is standard in much of the applied work in this area (for example, see Katz and Meyer, 1990).

This paper employs two econometric methodologies. First we use a nonparametric approach to estimate the survivor, hazard and integrated functions. This approach allows us to examine the pattern of duration dependence that exists in the data and is known to be useful in assisting with a choice of a parametric model. Second, we utilize the Cox (1972) proportional hazard model with time-varying covariates, which we estimate by maximizing the partial likelihood function in section 4. As previously mentioned, this second approach allows an examination of the various characteristics influencing the probability that a 
converted institution will issue an IPO. This estimation procedure is semi-parametric since no baseline hazard is specified. In what follows, we outline the details of our nonparametric estimation of the survivor, hazard and integrated hazard functions.

\section{Nonparametric Hazard Estimation}

In estimating the hazard function nonparametrically, we assume that the underlying process from conversion to IPO issue is continuous and as such, the survival time data we have are observations on a continuous variable. ${ }^{3}$ The key function that we estimate at this stage is the hazard function, which represents the instantaneous transition intensity in moving from a state where no event has occurred, to one where an event occurs (i.e. the institutions issue an IPO):

$$
\text { hazard }\left(t_{k}\right)=\frac{n o . \text { of converted credit unions issuing IPO at } t_{k}}{\text { no. of converted credit unions available to issue IPO at start of } t_{k}}
$$

For example for a small interval of time $\Delta t, \Delta t$ times the nonparametric estimate of the hazard rate at $t_{k}$ would tell us the probability of an event occurrence (i.e. that a converted credit union would issue an IPO) in $\left(t_{k}+\Delta t\right)$, conditional on having survived till $t_{k}$. By estimating this function, we obtain an idea of the pattern of duration dependence that exists in the data. In addition, we obtain estimates of the (integrated) hazard and survivor functions using the Kaplan-Meier product-limit estimators. The non-parametric estimates of these functions are generated as follows.

\footnotetext{
${ }^{3}$ We also consider an alternative assumption where we still assume that the underlying survival time process is continuous, but that we actually observe the survival time data in discrete intervals. Under this assumption, we employ lifetable methods to get estimates of the hazard, integrated hazard and survivor functions. The results from this method are depicted in figure 4 in Appendix A.
} 
Suppose that $t_{i 1}<t_{i 2}<\ldots<t_{i j}<\ldots<t_{i J_{i}}<\infty$ represents $\left(\mathrm{J}_{\mathrm{i}}-1\right)$ survival times for each bank $i$ that are observed in the data. The survivor function at time $t_{j}, S\left(t_{j}\right)$ represents the proportion of those institutions entering a state where they would issue an IPO in time $t_{j}+\Delta t$ conditional on having survived up until time $t_{j}$. In the context of this paper, the survivor function represents the proportion of converted credit unions who have not yet issued an IPO, conditional on not having done so up to that point in time. The KaplanMeier estimate of the survivor function is calculated as the product of one minus the number of exits (or events, i.e. where the institution issues an IPO) as a fraction of the risk set, i.e. the total number of institutions that are able to issue an IPO at that point in time. Hence, it is the product of one minus the exit rate at each of the survival times. The nonparametric estimate of the survivor function is calculated as:

$$
\hat{S}\left(t_{j}\right)=\prod_{j \mid t_{j}<t}\left(1-\frac{d_{j}}{n_{j}}\right)
$$

where $d_{j}$ represents the number of institutions observed to issue an IPO, and $n_{j}$ represents the total number of institutions at risk of ending their spell. $n_{j}$ consists of those who either have a completed spell, or a censored spell of length $t_{j}$ or longer. The integrated hazard function, $H\left(t_{j}\right)$ is estimated though the Nelson-Aalen estimator and constructed as:

$$
\hat{H}\left(t_{j}\right)=\sum_{j \mid t_{t}<t}\left(\frac{d_{j}}{n_{j}}\right)
$$

It should be noted that although we could have estimated the integrated hazard function by taking the negative of the natural log of the estimated Kaplan-Meier survivor function, we utilized the Nelson-Aalen estimator for a particular reason. Although both the Kaplan-Meier and Nelson-Aalen estimators are asymptotically equivalent, the Nelson-Aalen estimator is 
known to have better small sample properties when estimating the integrated hazard. Moreover, we are only able to derive estimates of $S(t)$ and $H(t)$ at dates where transitions are observed. The last estimate occurs at the transition of the institution with the largest noncensored survival time. Consequently, the estimates of both these functions are step functions, reflecting the lack of observed transitions to the state where IPOs are issued for every point in calendar time.

Furthermore, this has implications for estimating the hazard function. The non-parametric estimate of the hazard rate is not well defined and as such, even though the hazard rate should be able to be estimated as the derivative of the integrated hazard function, we are unable to do so since the non-parametric estimate of the integrated hazard yields a step function. However, the estimation of the hazard function is achieved by smoothing the estimated integrated hazard function using a kernel, and then differentiating the smoothed integrated hazard to yield the "smoothed hazard" function. ${ }^{4}$ Since the choice of bandwidth selection is known to be relatively more important than kernel selection in this literature, we consider one to four to be plausible values for the bandwidth parameter. This is because our data is in quarterly format and consequently we do not want to use observations outside the range of one year to influence the smoothing process. The smoothed hazard function which we estimate is presented in figure (2a), and it utilizes an Epanechinikov kernel with a bandwidth of $2 .^{5}$

\footnotetext{
${ }^{4}$ In the case of the alternative approach using the lifetable estimators, where we view the observations as having been grouped into intervals, we derive estimates of the interval hazard rate by dividing the time axis into regular intervals of time. See figure 4(c) in Appendix A.

5 The results which we present here are robust to the use of alternative kernels as well as for the plausible values of the bandwidth parameter which we consider above.
} 
The results from these estimations are reported in figures (1) and (2), where the survival time data is measured in quarters. As can be seen in figure 1(a), the survivor function shows that the median duration occurs between 17 - 18 quarters. By the end of the sample, approximately one tenth of the converted institutions who have not issued an IPO will continue to (not) do so. Eyeballing figure 1(b), the estimate of the integrated hazard, would appear to suggest that the hazard function increases slowly, declines a bit and then levels off. We are able to see that to some extent in figure 2(a) from our estimated smooth hazard function, which shows the extent of the positive duration dependence observed in the data. The presence of the positive duration dependence indicates increasing transition intensities, suggesting an increasing probability of an IPO issue that eventually peaks at 32 quarters. However, it is interesting to note that there is an initial peak in transition intensity at 15 quarters of lesser magnitude prior to the large peak at 32 quarters. This is also reflected in figure 2(b) which depicts the change in the integrated hazard between successive events, and thus reflects the contribution of the hazard function to the integrated hazard function. Here we see large change in the hazard from the $12^{\text {th }}$ quarter onwards, as well as a much larger contribution from approximately 30 quarters and thereafter.

The pattern of duration dependence from the figures here would suggest that a small proportion of converted credit unions in the data that issue an IPO, may do so relatively early at anytime between three and a half years to four years having converted. The majority of those credit unions that convert and subsequently issue an IPO, do so approximately by eight years once they have converted. The factors that contribute towards issuing early or issuing later cannot be determined from the nonparametric estimates. However further information may be gleaned from the second part of this paper where we proceed to 
examine the factors that contribute towards this pattern of duration dependence by estimating the Cox (1972) proportional hazard model with time varying covariates.

\section{Modeling the Time to an IPO Issue}

As mentioned above, we wish to identify the characteristics of the converted credit union that contribute towards the probability of an IPO issue. We model the time till an IPO issue using the semi-parametric Cox (1972) proportional hazard model with time-varying covariates, which we estimate by maximizing the partial likelihood function. Given this framework, the underlying (continuous time) hazard function for an IPO issue can be written as $h_{i}\left(t \mid \mathbf{x}_{i}(t), \boldsymbol{\beta}\right)$, where $\mathrm{i}=1, \ldots, \mathrm{n} ; \mathbf{x}_{\mathrm{i}}(\mathrm{t})$ are vectors of time-varying independent variables (or covariates as it is known in the literature) and $\boldsymbol{\beta}$ is a vector of parameters to be estimated.

Following the notation used by Wheelock and Wilson (2000), suppose that $t_{i 1}<t_{i 2}<\ldots<t_{i j}<\ldots<t_{i J_{i}}<\infty$ represents $\left(J_{i}-1\right)$ distinct survival times for each bank $i$ that are observed in the data. At time $t_{i J_{i}} \geq t_{i J_{i}-1}$, we observe either an event (i.e. IPO issue), or the observation on the $i$ th institution is censored at that point in time. The vector of timevarying covariates, $\boldsymbol{x}_{i}(t)$, corresponding to time $t_{i p} \quad j=1, \ldots,\left(J_{i}-1\right)$ is assumed to reflect observed measurable characteristics of bank $i$, over the interval $\left[t_{i j}, t_{j+1}\right)$ for $j=1, \ldots,\left(J_{i}-1\right)$. This hazard model contains time-varying covariates in the sense that these covariates may vary across intervals, $\left[t_{i j}, t_{i j+1}\right)$, although they are assumed to be constant within the intervals of time.

In estimating this model we use the partial likelihood approach suggest by Cox $(1972,1975)$, where we define the indicator variables: 


$$
f_{i}=\left\{\begin{array}{l}
1 \text { if bank } i \text { issues IPO, i.e. event occurs } \\
0 \text { otherwise }
\end{array}\right.
$$

Thus, the contribution by the $i$ th bank to the partial likelihood is:

$$
L_{i}\left(\beta_{i}\right)=\frac{h_{i}\left(t_{J_{i}} \mid x_{i}\left(t_{J_{i}}\right), \beta\right)^{f_{i}}}{\sum_{m \in R_{i}} h_{i m}\left(t_{J_{i}} \mid x\left(t_{J_{i}}\right), \beta\right)}
$$

where $R_{i}=\left\{m \mid t_{J_{m}} \geq t_{J_{i}}, m=1, \ldots, N\right\}$ is the risk set associated with bank $i$ (i.e. the set of banks that have not issued an IPO before bank $i$ did). It should be noted that the censored institutions do not contribute to the partial likelihood in the numerator, although they do enter the denominator. We specify the proportional hazard as

$$
h_{i}\left(t \mid x_{i}(t), \beta_{i}\right)=\bar{h}(t) \exp \left(x_{i}(t) \beta\right)
$$

where $\bar{h}$ is the baseline hazard. Substituting this into equation (4), taking logs and summing across all individual banks yields the partial log likelihood for the entire sample:

$$
\log L(\beta)=\sum_{i=1}^{N}\left\{f_{i} x_{i}\left(t_{J_{i}}\right) \beta-\log \left[\sum_{m \in R_{i}} \exp \left(x_{m}\left(t_{J_{i}}\right) \beta\right)\right]\right\}
$$

The advantage of this partial likelihood approach is that in estimating the vector of parameters $\boldsymbol{\beta}$, only a part of the hazard needs to be specified. As a result of the structure of the partial likelihood function given in equation (4) and the proportional hazards assumption, we do not have to define the density or survivor functions, or specify the baseline hazard, $\bar{h}$, since it drops out when equation (5) is inserted into equation (4). This feature of the model is particularly useful when estimating the model since it allows us to directly estimate the vector of parameters $\boldsymbol{\beta}$ in the hazard function without needing to 
specify the underlying density or survivor functions, even in the presence of endogenous regressors. ${ }^{6}$

\section{Hazard Model Specification}

The previous section used a nonparametric approach to highlight the presence of positive duration dependence in the data. An important factor in trying to explain the overall increasing probability of an IPO issue is the choice of covariates to include. We consider two key reasons why a converted credit union may issue an IPO and these reasons are fundamentally different. The first reason is based on a profit motive and arises from a desire by insiders to garner an economic transfer of wealth (as mentioned in the introduction). The second reason arises from an intrinsic need to raise additional capital due to liquidity needs and/or poor loan portfolio performance. Our choice of covariates should be able to capture the effects of these varied reasons. We follow a balance sheet perspective and assume that items on the balance sheet of the bank are sufficient statistics that will allow us to account for these two reasons as to why an institution might pursue demutualization and issue an IPO.

Most of the covariates we choose for the model are standard within the literature on bank failures and acquisitions (see for example, Wheelock and Wilson, 2000). We focus on measures of capital adequacy, asset quality, earnings, and liquidity factors that might influence the probability that a converted credit union issues an IPO. In order to capture the measures mentioned above, we incorporate the following (time-varying) covariates:

\footnotetext{
${ }^{6}$ See Lancaster (1990) pp. 21 - 32 for a detailed discussion.
} 


\section{Baseline Variables}

- Capital Adequacy:

- $\quad$ TETA $=$ Total Equity $/$ Total Assets

- Asset Quality:
o ROA $=$ Return on Assets
o $\mathrm{ROE}=$ Return on Equity
o NPL $=$ Non Performing Loans/Total Loans
o $\mathrm{NPA}=($ Non Performing Assets +90 Days Past Due $) /$ Total Assets
o $\quad$ TLTA $=$ Total Loans $/$ Total Assets

- Earnings:

o $\quad \mathrm{EARN}=$ Net income $/$ Total Assets

- Liquidity:

o $\quad$ LIR $=$ Liquidity Ratio

- Miscellaneous Factors:

- BRANCHES $=$ Number of branches

o $\quad$ SIZE $=\log$ of total assets

Considering the variables specified above, we begin by focusing on measures that primarily influence the probability of an IPO issue due to the wealth motive outlined earlier. These measures include: TETA; ROA; ROE; NPA; EARN; BRANCHES and SIZE. The characteristics of converted credit unions that are primarily intended to influence the probability of an IPO issue due to the second reason - a need to raise capital - include: NPL; TLTA; EARN and LIR.

In estimating the hazard, we expect the coefficient on TETA to have a positive sign, indicating that banks with higher equity as a percentage of total assets will be more likely to issue an IPO. The intuition here is because the more equity a bank has, the greater the amount of protection it has against declines in the value of its assets or against losses from 
loans. In addition, a larger value here would also be indicative of the idea that the converted institution is seen as profitable and hence is an attractive investment, whether the underlying fundamental reason behind the IPO issue is one of wealth accumulation by insiders, or if it is in an effort to raise capital through an initial public offering. Based on similar intuition to that above, we would expect a positive sign for ROA and ROE, where these would be viewed as indicators of the state of an institution's balance sheet and profitability. However, a high ratio of non performing assets and past due to total assets, NPA, would be indicative of a bank that has poor asset performance and this would decrease the probability of an IPO since the converted institution would not be seen as being profitable. Hence, we would expect a negative sign on NPA.

Focusing on measures of asset quality, typically loans are the part of bank's assets which are the most risky, as well as being the least liquid. A high ratio of non performing loans to total loans, NPL would indicate that the quality of a bank's loan portfolio is low, and hence engender the need for an IPO to raise capital. By a similar argument, the higher the fraction of total loans to total assets, TLTA, the more this would indicate a concentration of bank's assets in loans. Thus we would expect that the signs on NPL and TLTA to be positive since these variables are related to the second motive for issuing an IPO.

In a similar vein, we would expect successful banks with high liquidity to have less of a need to issue an IPO in order to raise capital. Thus the coefficient on LIR is expected to be negative. However, with regards to EARN, we are unsure of the likely sign to expect. This is because earnings would have an impact on the probability of an IPO issue for both reasons outlined above. A bank with higher net income would be viewed as profitable suggesting a 
positive sign on the coefficient. However, the greater the net income, the less the need for a bank to issue an IPO due to a need to raise capital, indicating a negative sign for the coefficient. Hence, the ambiguity about the sign on the coefficient arises without knowing which of these effects will dominate.

With regards to the final set of covariates, BRANCHES, and SIZE, we would expect a positive sign on both. For BRANCHES, this is because a greater number of available branches would typically indicate a successful bank and thus we would expect a positive sign because of the profit reason. We expect a positive sign on SIZE since casual empiricism would suggest that smaller institutions would be less successful in an IPO issue.

It should be noted that when considering the variables specified above, it is possible that several of the variables may be endogenous with regards to the survival times. However, as pointed out earlier, Lancaster (1990) notes that the advantage of the partial likelihood estimation approach is that only a part of the hazard function needs to be specified. In particular, the baseline hazard, $\bar{h}$, drops out when equation (5) is inserted into equation (4), and as a result, we are able to avoid the problems associated with endogeneity since we do not need to specify (or parameterize) the underlying survivor or density functions.

\section{Estimation Results}

The results from the estimation of the Cox's (1975) partial likelihood model are reported in Table 2. Results are shown for estimates of the slope coefficients, $\boldsymbol{\beta}$, as well as the corresponding hazard ratio, $\exp \left(\beta_{k}\right)$ for each covariate, $k$. Regarding the coefficients on the covariates, a positive sign indicates that an increase in that covariate is associated with an 
increase in the IPO hazard, just as a negative sign indicates an increase in the covariate is associated with a decrease in the IPO hazard.

The value of the coefficient itself indicates the proportional effect on the hazard from absolute changes in the corresponding covariate, conditioned on a given survival time (since we have time varying covariates). The hazard ratio represents the proportionate change in the hazard given a unit change in covariate $k$, holding all other covariates fixed, again conditioned on a given survival time. ${ }^{7}$

The qualitative results (in terms of the sign on the coefficient) on the whole appear to be consistent with our predictions. The only exception is for the ratio of total loans to total assets, TLTA, where the coefficient is negative. However, the coefficient on TLTA turns out to be insignificant. For the remaining covariates, our measure of capital adequacy, TETA, along with three of the five measures of asset quality turn out to be significant and of the correct sign: ROE, NPL and NPA. NPL, NPA and TETA are all significant at five percent, with the latter being significant at one percent. A test of joint significance on all the coefficients yields a significant value for the likelihood ratio test, suggesting that the coefficients are not all equal to zero.

7 To see this, using equation (5), suppose that for banks i and j, $x_{i z}=x_{j z} \forall z \in\{1, \ldots, Z \backslash k\}$ for some given survival time $\bar{t}$ and construct the ratio as: $\frac{h\left(\bar{t}, x_{i}\right)}{h\left(\bar{t}, x_{j}\right)}=\exp \left[\beta_{k}\left(x_{i k}-x_{j k}\right)\right]$. Then, for $x_{i k}-x_{j k}=1$, then $\frac{h\left(\bar{t}, x_{i}\right)}{h\left(\bar{t}, x_{j}\right)}=\exp \left(\beta_{k}\right)$ 
We can interpret the coefficients and hazard ratios as mentioned above. For example from the results above, an absolute change in the total equity to total asset ratio, $\Delta$ TETA, would yield a proportionate increase in the hazard rate of $0.422^{*} \Delta$ TETA. Moreover, if all banks had the same value for the other covariates, then a $1 \%$ increase in TETA would increase the hazard rate by $1.525 \%$. Both of these examples are conditioned for some given value of the survival time.

Interestingly, neither the return on asset, ROA, nor the ratio of total loans to total assets, TLTA, appears to be significant. The evidence above would appear to suggest that assets in themselves do not play a large role in influencing the IPO hazard, but rather that measures of equity are better able to capture the effect on the probability of an IPO issue. This result appears to be contrary to what one would expect, since assets in general are thought to be positively related to the profitability of institution viewed as an investment opportunity. This is further evidenced by the coefficient on the log of total assets, SIZE, which is insignificant. The results here would suggest that the probability of an IPO issue is largely equity driven. However, an IPO issue based on a need to raise additional capital also appears to play a role through the presence of a significant coefficient on NPL. We report the baseline survivor and integrated hazard functions generated from this estimation in figure (3) as a matter of interest.

To investigate the equity driven effect on the probability of an IPO issue further, we also estimate Cox's (1975) partial likelihood model again but include an additional variable to the baseline variables listed above. The second specification also includes TETA2, where 
TETA2 is the ratio of total equity to total assets, squared, i.e. $\left(\frac{\text { Total Loans }}{\text { Total Assets }}\right)^{2}$. We include this variable since we wish to examine the additional extent to which converted credit unions with a very high or low ratio of equity to assets desire to (- or are able to in the case of a really low ratio) issue an IPO. The results are reported in Table 3.

Since we are focusing on the equity driven effect on the probability of an IPO issue, we would expect that the other factor which influence the probability of an IPO issue, i.e. due to an intrinsic need to raise capital, will be insignificant. This is what we see in Table 3, where NPL now is insignificant. The other variables which were insignificant in our earlier estimation remain so. In addition, NPA, which was significant earlier, is now insignificant. The coefficient of interest is the one for TETA2. This coefficient is negative and significant at the 5 percent level.

The presence of this negative coefficient suggests that banks with a low value of total equity to total assets and those with really high values of total equity to total assets are less likely to issue an IPO. The intuition behind this can be thought of as follows. Consider first the banks with a low ratio. These will not be viewed as profitable and hence are not likely to be an attractive candidate as an investment opportunity. Conversely, banks with a very high ratio of total equity to total assets are also unlikely to issue an IPO. We believe the reasoning here is because these banks are less likely to use an IPO issue to raise capital. 


\section{Conclusions}

The last decade has seen the beginnings of a movement amongst credit unions to convert to mutual savings banks following the Credit Union Membership Act of 1998. Subsequently, many of these converted institutions have gone on to demutualize and convert to publicly traded banks. This paper explores this process within the context of a duration model framework and examines the hazard function associated with an initial public offering (IPO) as well as the various factors that influence the converted credit unions to issue an IPO.

There are three key findings in the paper. The first finding highlights the presence of positive duration dependence in the data. This reflects increasing probabilities that converted credit unions will issue an IPO. Moreover, these hazard function increases in two waves. The first spike occurs between three and a half years to four years, indicating an increase in the probability of issuing an IPO. Converted institutions that are ready to demutualize early, will do so by then. The majority of converted institutions who do demutualize, do so by approximately eight years reflecting the second spike in the hazard function.

Finally, we find that measures of asset quality that focus on equity and the quality of a bank's loan or asset portfolio are the particular factors that can be associated with a converted institution's decision to issue an IPO. Notably, we find that using ROA, total loans to total assets and finally log of total assets do not appear to be associated with a converted institution's decision to issue an IPO. Rather, the probability that a converted credit union will issue an IPO appears to be equity driven. Focusing on equity, we find that banks with either low or very high ratios of equity to assets are less likely to issue an IPO. 
The conversion of credit unions to mutual savings banks is promoted as a business tactic that seeks to expand the customer base and the products available to the saver and the borrower. While this goal is reasonable, the rapid reconversion appears to discredit that approach. The rapid demutualization appears to be part of the initial mutualization process. If the process is to be considered credible, the incentives for demutualization should be limited.

These incentives include management compensation. Bank CEOs typically receive much greater compensation than credit unions CEOs, with the bank CEOs receiving from $20 \%$ to $57 \%$ more for institutions of similar assets size (Theriault, 2002). In addition, bank directors are typically compensated and provided travel and expense allowances, while credit union directors are uncompensated in almost every instance. Finally, the gap in pay can be much wider at individual banking institutions that utilize stock compensation programs. By limiting the initial compensation provided to insiders for several years, the appearance of unjust enrichment can be limited. 


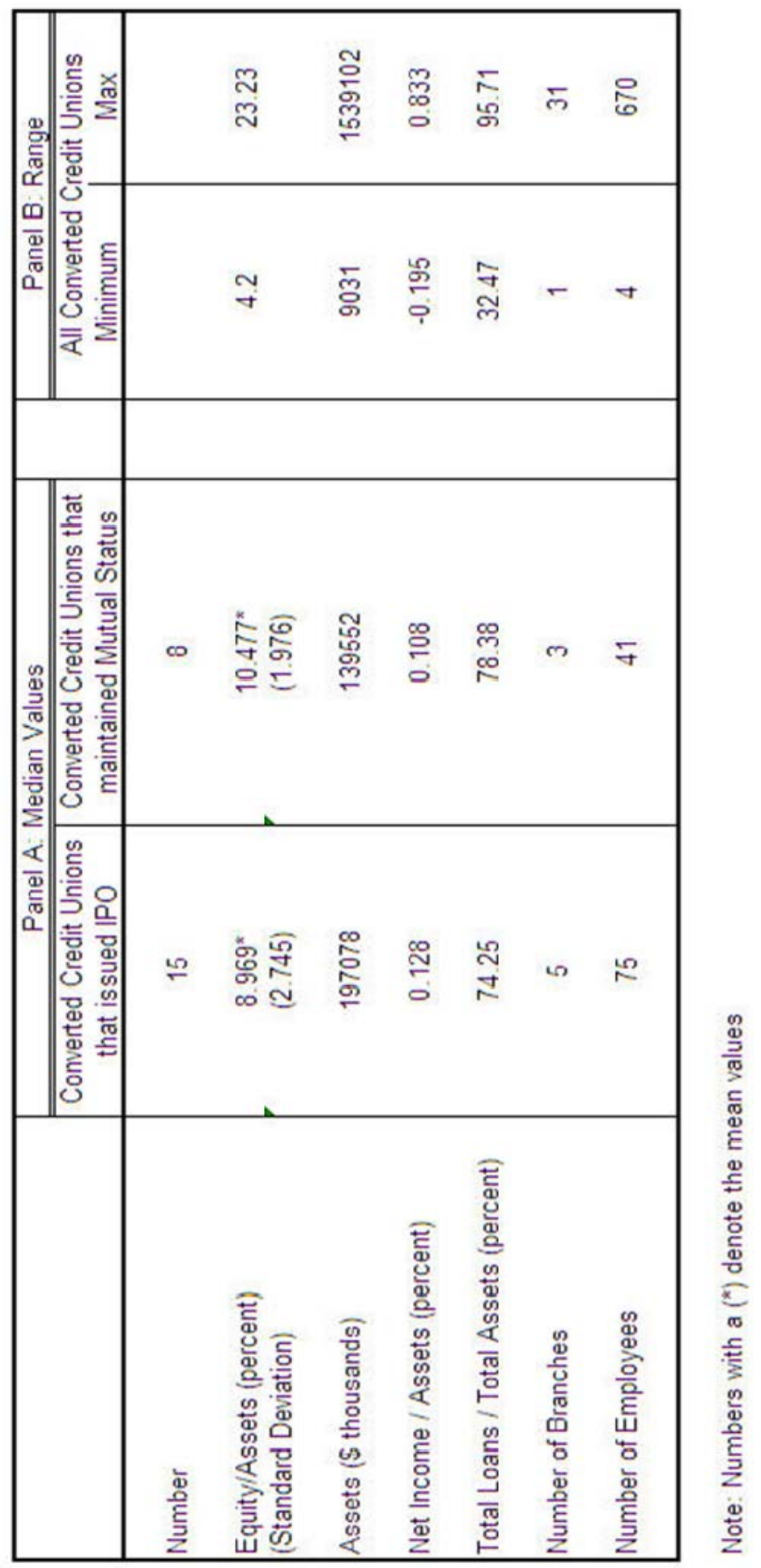

Table 1: Descriptive statistics characterizing the data 


\begin{tabular}{|c|c|c|c|c|c|}
\hline Survival Time, $\mathrm{t}$ & Coef. & Std. Err. & Haz. Ratio & Std. Err. & P-value \\
\hline$\overline{\text { teta }}$ & $0.422^{\star \star \star}$ & $(0.145)$ & 1.525 & $(0.221)$ & 0.004 \\
\hline roa & 3.839 & (9.632) & 46.495 & $(447.858)$ & 0.690 \\
\hline roe & $0.072^{*}$ & $(0.040)$ & 1.075 & $(0.043)$ & 0.070 \\
\hline npl & $0.805^{\star \star}$ & $(0.380)$ & 2.236 & $(0.851)$ & 0.035 \\
\hline npa & $-1.977^{\star \star}$ & $(0.865)$ & 0.139 & $(0.120)$ & 0.023 \\
\hline tlta & -0.079 & $(0.061)$ & 0.924 & $(0.057)$ & 0.195 \\
\hline earn & -1670.495 & (4032.061) & 0.000 & $(0.000)$ & 0.679 \\
\hline lir & -0.053 & $(0.055)$ & 0.949 & $(0.052)$ & 0.336 \\
\hline branches & 0.057 & $(0.064)$ & 1.059 & $(0.067)$ & 0.369 \\
\hline size & 0.282 & $(0.452)$ & 1.326 & $(0.600)$ & 0.534 \\
\hline No. of subjects & 23 & & Log likelihood & -24.2676 & \\
\hline No. of failures & 15 & & & & \\
\hline Time at risk & 358 & & LR Test & 21.87 & \\
\hline Number of obs & 358 & & Prob & 0.0158 & \\
\hline
\end{tabular}

Note: $\left(^{\star}\right)$ indicates $10 \%$ level of significance; $\left(^{\star \star}\right) 5 \%$ significance; $\left(^{\star \star \star}\right) 1 \%$ significance

Table 2: Results from Cox’s (1975) Partial Likelihood Estimation 


\begin{tabular}{|c|c|c|c|c|c|}
\hline Survival Time, $\mathrm{t}$ & Coef. & Std. Err. & Haz. Ratio & Std. Err. & P-value \\
\hline teta & $1.182^{\star \star}$ & $(0.573)$ & 3.261 & $(1.869)$ & 0.040 \\
\hline teta2 & $-0.029 * \star$ & $(0.014)$ & 0.971 & $(0.013)$ & 0.036 \\
\hline roa & 4.550 & (9.199) & 94.623 & (870.406) & 0.621 \\
\hline roe & $0.150^{* *}$ & (0.068) & 1.162 & $(0.079)$ & 0.028 \\
\hline $\mathrm{npl}$ & 0.030 & (2.259) & 1.031 & (2.328) & 0.989 \\
\hline npa & -1.023 & (2.909) & 0.360 & (1.046) & 0.725 \\
\hline tlta & -0.090 & $(0.068)$ & 0.914 & $(0.062)$ & 0.185 \\
\hline earn & -2241.737 & (3945.717) & 0.000 & $(0.000)$ & 0.570 \\
\hline lir & -0.058 & $(0.061)$ & 0.944 & $(0.058)$ & 0.341 \\
\hline branches & 0.073 & $(0.072)$ & 1.076 & $(0.077)$ & 0.308 \\
\hline size & 0.200 & $(0.523)$ & 1.222 & $(0.640)$ & 0.702 \\
\hline No. of subjects & 23 & & Log likelihood & -23.186 & \\
\hline No. of failures & 15 & & & & \\
\hline Time at risk & 358 & & LR Test & 24.04 & \\
\hline Number of obs & 358 & & Prob & 0.0126 & \\
\hline
\end{tabular}

Note: $\left(^{\star}\right)$ indicates $10 \%$ level of significance; $\left(^{\star \star}\right) 5 \%$ significance; $\left(^{\star \star \star}\right) 1 \%$ significance

Table 3: Results from estimation on the effect of equity 


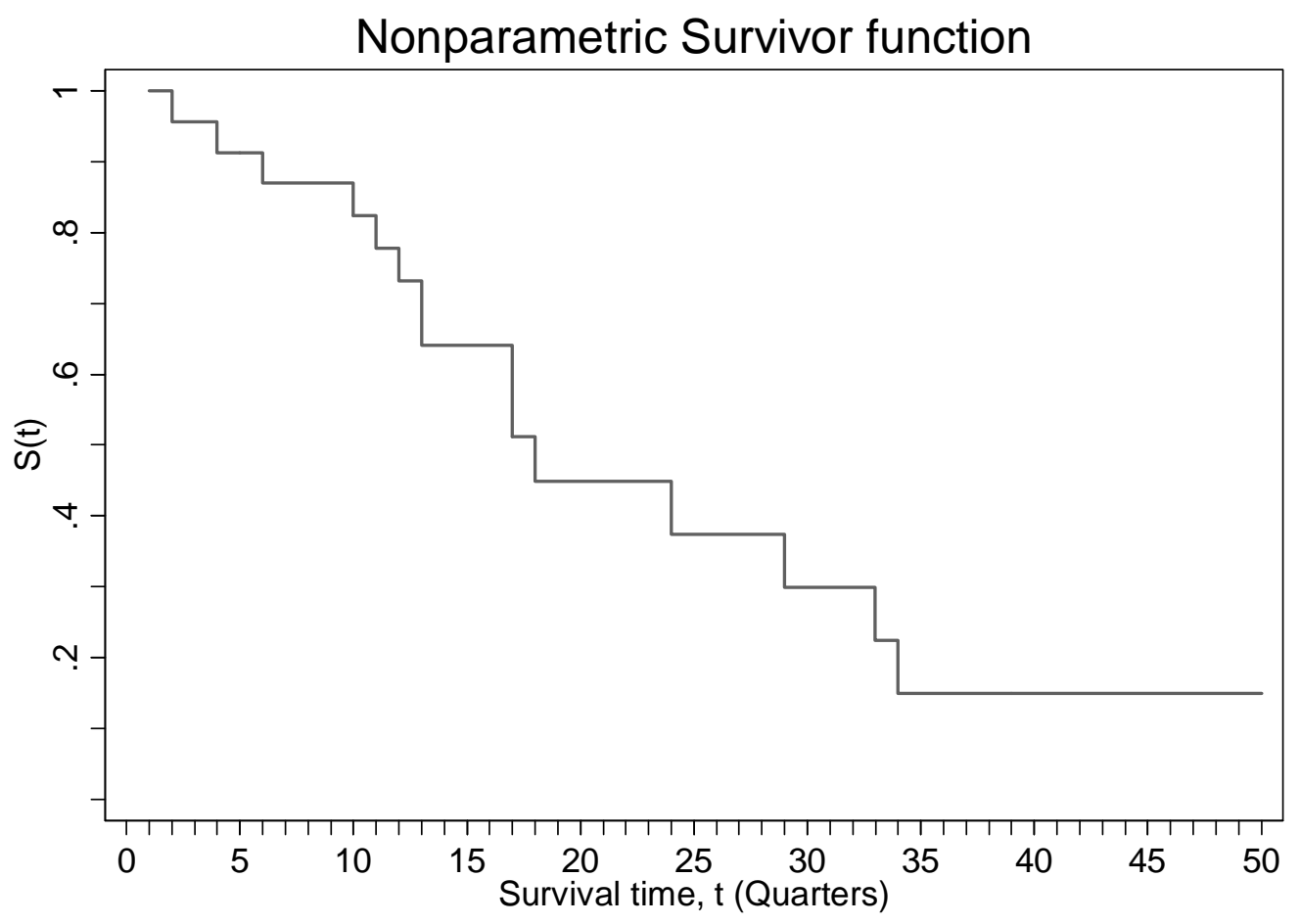

Figure 1a: Estimated non-parametric Survivor function

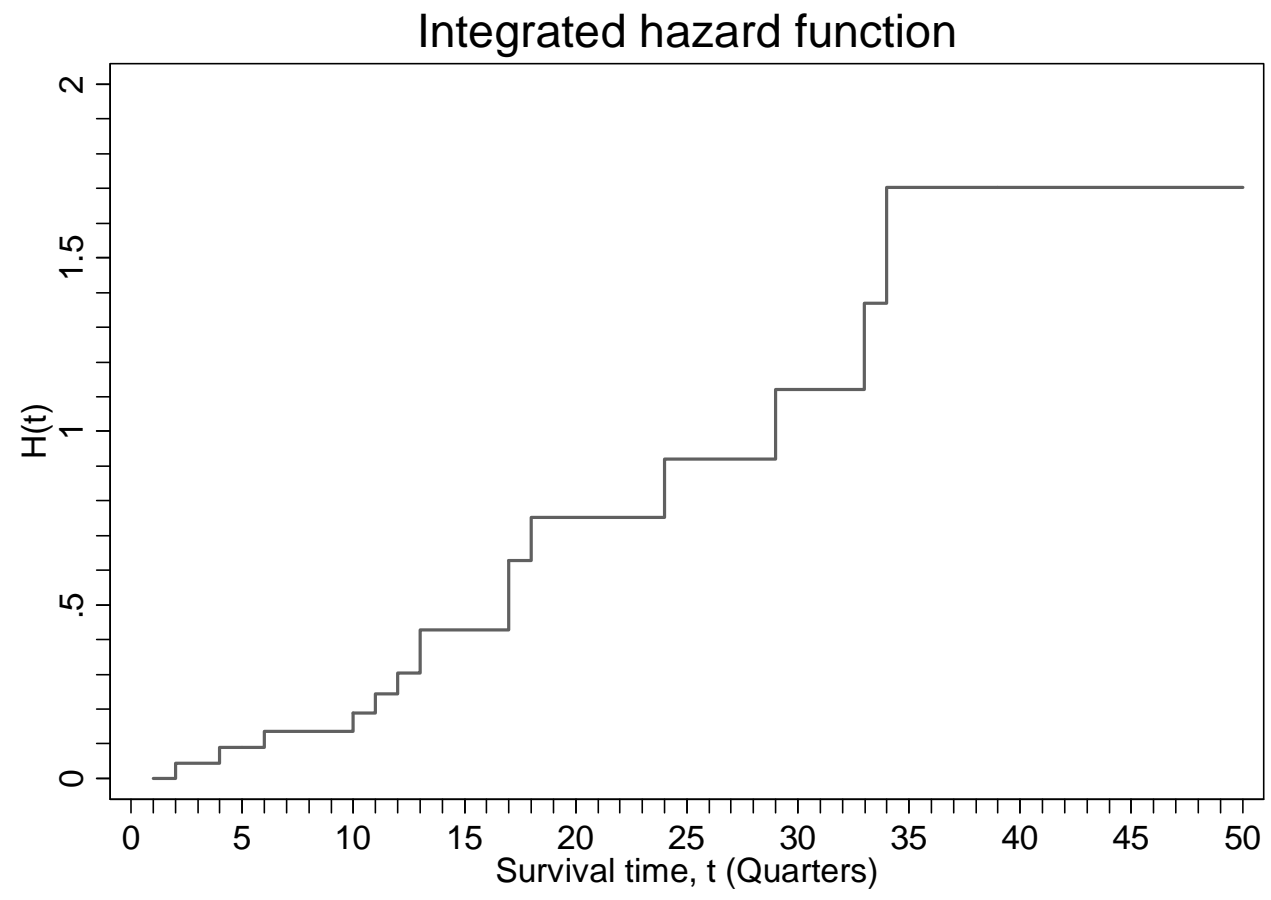

Figure 1b: Estimated non-parametric Integrated Hazard function

Figure 1: Results of non-parametric estimation of hazard functions 


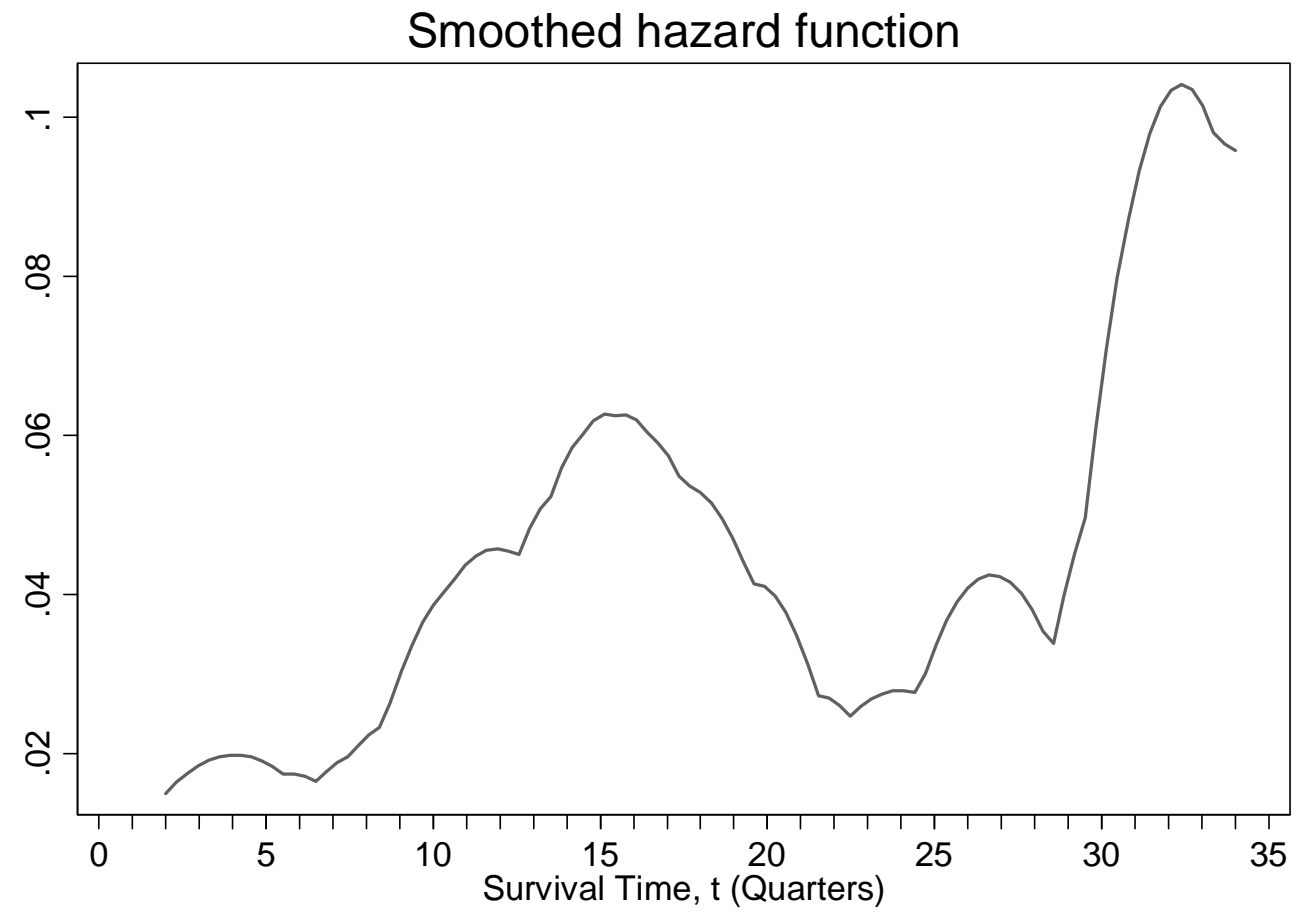

Figure 2a: Estimated "smoothed" hazard function Note: Kernel bandwidth $=2$

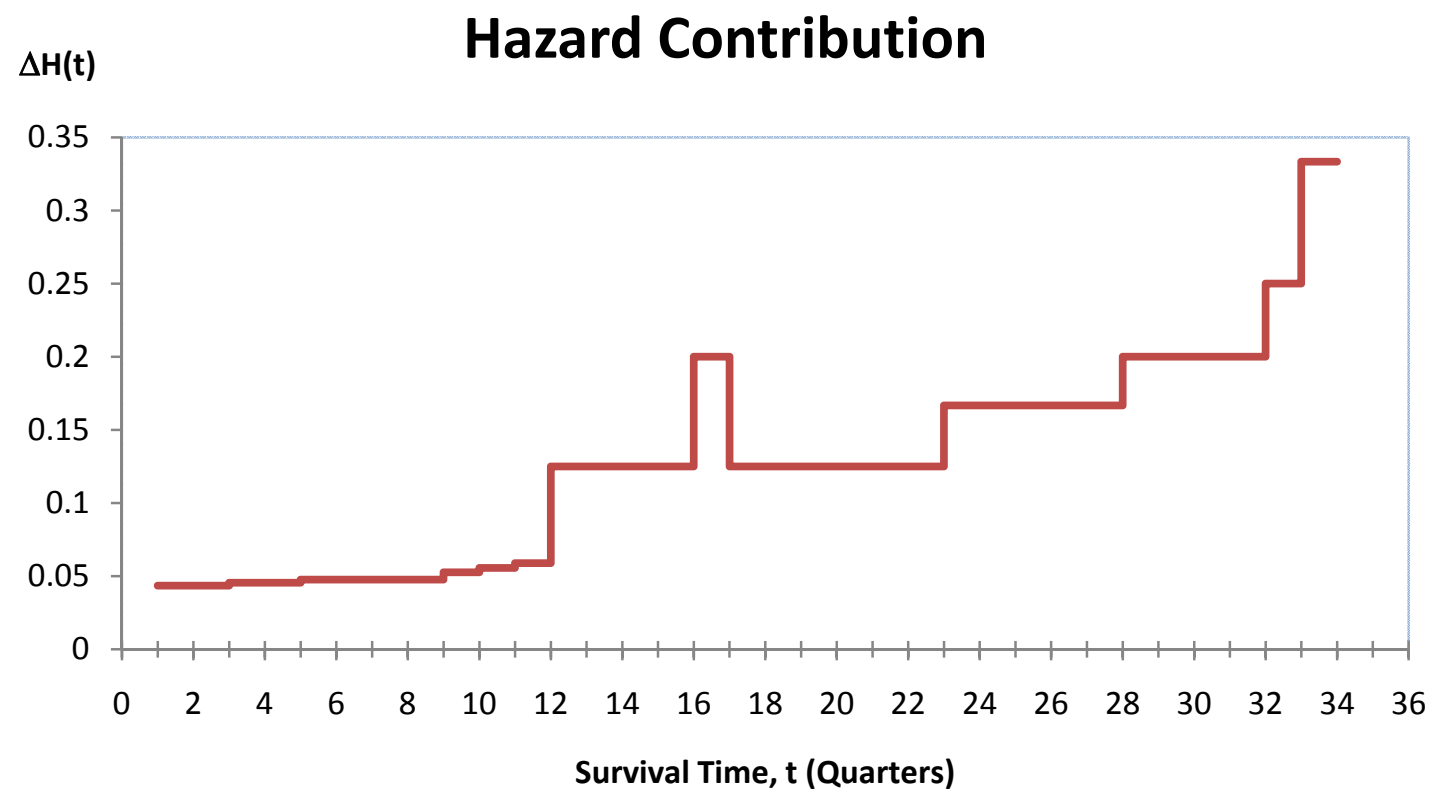

Figure 2b: Changes in the integrated hazard between successive IPO issues

Figure 2: Estimates of the Hazard Function 


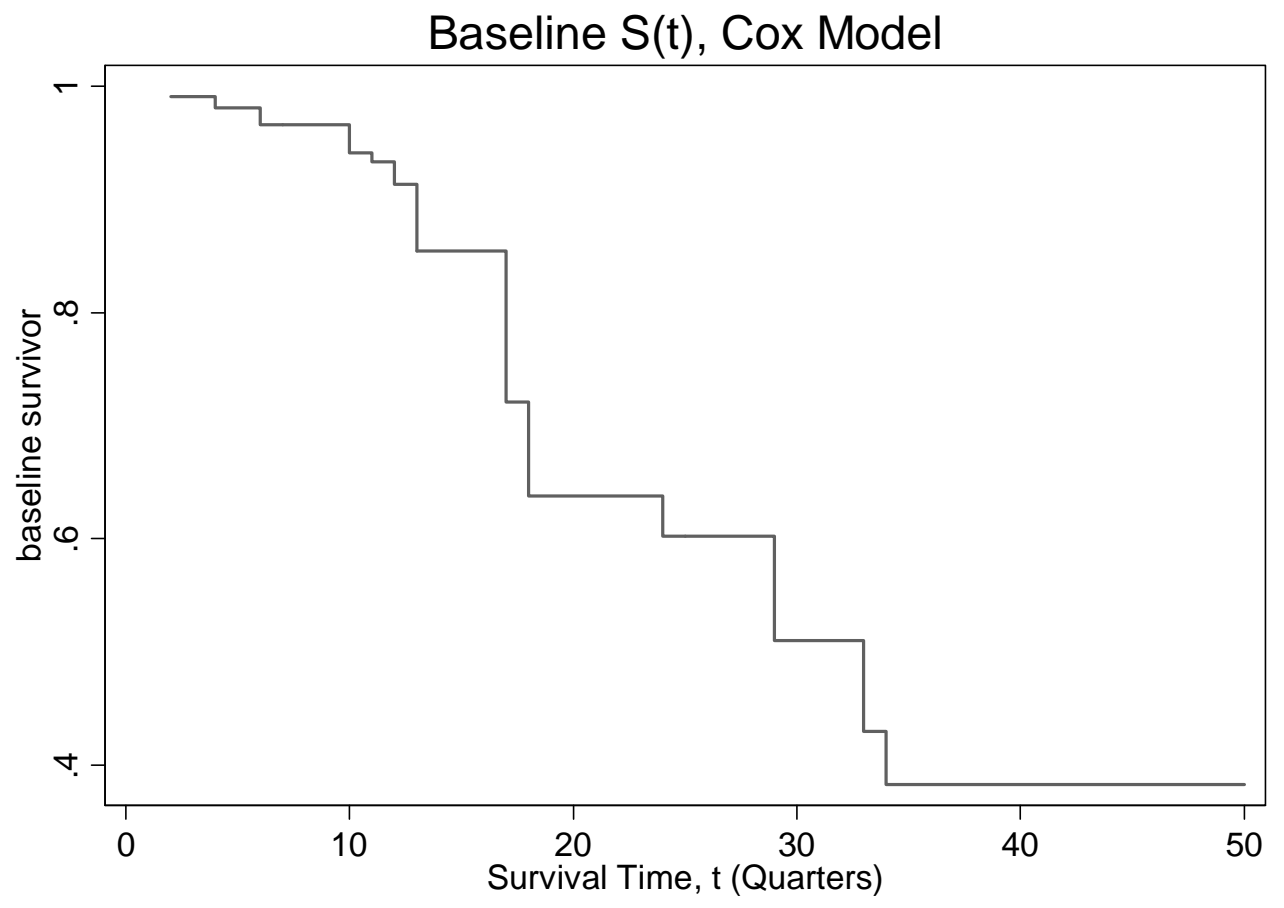

Figure 3a: Nonparametric estimate of the Baseline Survivor Function

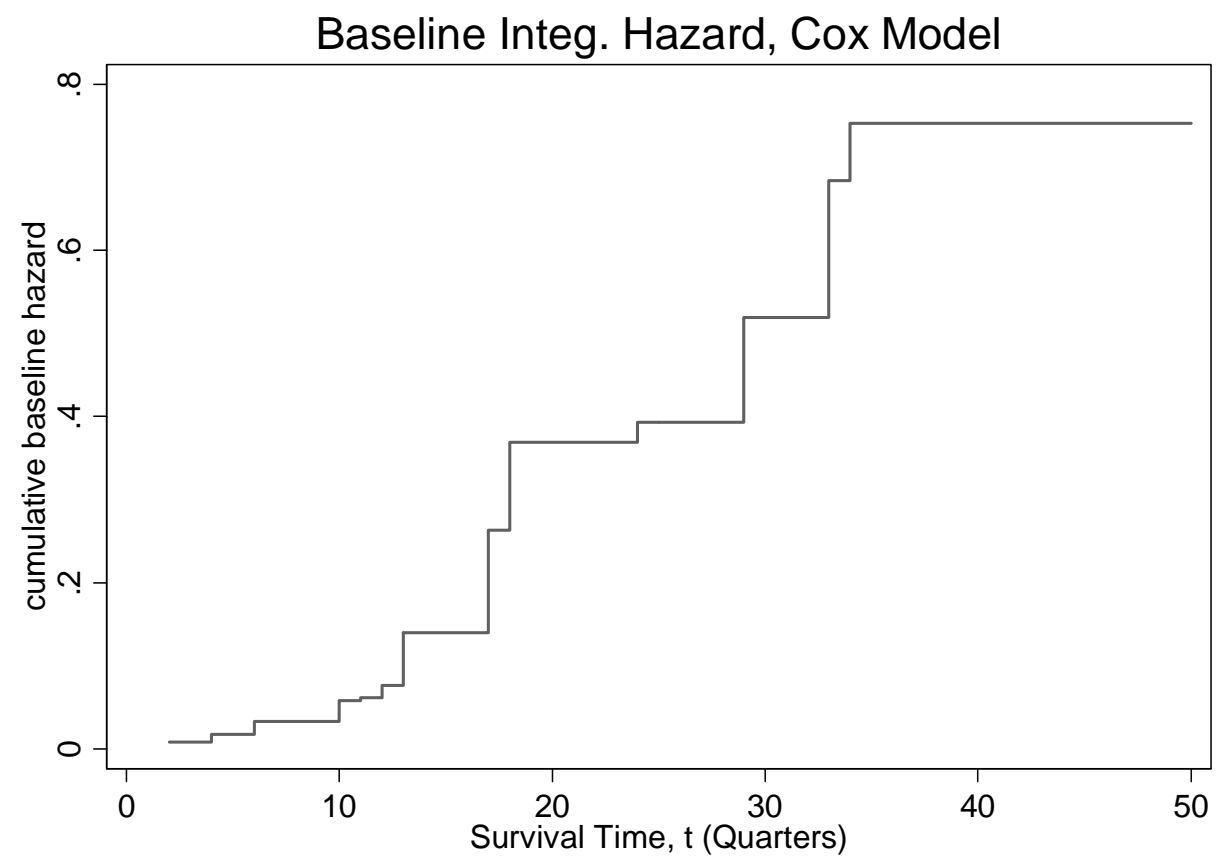

Figure 3b: Nonparametric estimate of the Baseline Integrated Hazard Function

Figure 3: The Baseline Survivor and Integrated Hazard Functions 


\section{References}

Aalen, O. O. (1978), "Non parametric inference for a family of counting processes", Annals of Statistics, Vol. 6, pp. 701-726

Beatty, R. P. and J. R. Ritter (1986), "Investment Banking, Repuration , and the Underpricing of Initial Public Offerings", Journal of Financial Economics, Vol 15:1-2, pp. 213-232.

Chaddad, F. R. and M. L. Cook (2004), "The Economics of Organization Structural Changes: A US Perspective on Demutualization”, Annals of Pubic and Cooperative Economics, Vol 75:4, pp. 575-594.

Cole, R. A, and H. Mehran (1998), “The Effect of Changes in Ownership Structure on Performance: Evidence from the Thrift Industry", Journal of Financial Economics, Vol 50, pp. 291-317.

Cox, D. R. (1972), "Regression Models and Life-Tables (with discussion)", Journal of the Royal Statistical Society, Vol. 34B, pp. 187-220 - (1975), "Partial Likelihood”, Biometrika, Vol. 62, (1975), pp. 269-276.

Feinberg, R. (2002), “Credit Unions: Fringe Suppliers or Cournot Competitors?”, Review of Industrial Organization, Vol. 20. pp 105-113. (2003), “The Determinants of Bank Rates in Local Customer Lending markets:

Comparing Market and Institutional Level Results”, Southern Economic Journal, Vol. 70. pp 144-156.

----------- (2004), “An Analysis of the Benefits of Credit Unions to Bank Loan Customers", mimeo, American University.

Feinberg, R and A.F.M. Rahman (2001), “A Causality Test of the Relationship between Bank and Credit Union Lending Rates in Local Markets", Economic Letters, Vol. 71. pp 271-275. (2006), “Are Credit Unions Just Small Banks? Determinants of

Loan Rates in Local consumer Lending Markets.", Eastern Economic Journal, Vol. 32(4), pp 647-659.

Focarelli, D. and F. Panetta (2003), “Are Mergers Beneficial to Consumers? Evidence from the Market for Bank Deposits", American Economic Review, Vol. 93. pp 1152-1172.

Hanan, T. (2002), “The Impact Of Credit Unions On The Rates Offered For Retail Deposits By Banks and Thrift Institutions", Finance and Economics Discussion Series Working Paper \#2003-6, Federal Reserve Board

Heinrich, J. and R. Kashian (2007), "Credit Union to Mutual Conversion: Do Rates Diverge?", Contemporary Economic Review, forthcoming 
Jordan, B. D., J. A. Verbrugge and R. M. Burns (1988), "Return to Initial Shareholders in Savings Institution Conversions", Journal of Financial Research, Vol. 11:2, pp. 125-136.

Kashian, R. and K. Monaco (2003), "The Pricing of Thrift Conversions", Journal of Applied Business Research. Vol 19, 2003 pp 25-31.

Katz, L. F. and B. D. Meyer (1990), "Unemployment Insurance, Recall Expectations, and Unemployment Outcomes", Quarterly Journal of Economics, Vol. 105, pp. 973 - 1002.

Lancaster, Tony (1990), The Econometric Analysis of Transition Data, Cambridge: Cambridge University Press, 1990.

Maksimovic, Vojislav and Haluk Unal. 1993. "Issue Size choice and "Underpricing" in Thrift Mutual-toStock Conversions", Journal of Finance 48: 1659-1692.

Masulis, W. Ronald. 1987. Changes in Ownership Structure: Conversions of Mutual Savings and Loans to Stock Charter". Journal of Financial Economics 18: 29-59.

Mehran, H. and S. Peristiani (2007), "Financial Visibility and the Decision to Go Private", unpublished manuscript, Federal Reserve Bank of New York.

Nelson, W. (1972), "Theory and applications of hazard plotting for censored failure data", Technometrics, Vol. 14, pp. 945-966.

Pagano, M., F. Panetta, and L. Zingales (1998), "Why Do Companies Go Public? An Empirical Study", Journal of Finance, Vol 53:1, pp. 27-64.

Peristiani, Stavros and Thiery A. Wizman. 1997. "Mutual-to-Stock Conversions in the Thrift Industry in the 1990s". Journal of Economics and Business, Vol. 49:2, pp. 95-116.

Srinivasan, A. and B. F. King (1998), "Credit Union Issues", Federal Reserve Bank of Atlanta: Economic Review, Vol. 3, pp 32-41.

Theriault, Alan D. (2002), “CEO \& Directors: Salary Imbalance is Corrected by Converting to a Bank", in Converting from a Credit Union Fax Update, Sept. 16, 2002, available at http://www.cufinancial.com/pdfs/NL2002.pdf.

Tokle, R. (2005), “An Estimate of the Influence of Credit Unions on Bank CD and Money Market Deposits in the US.”, Mimeo, Idaho State University.

Tokle, R. and J. Tokle (2000), “The Influence of Credit Union and Savings and Loan Competition on Bank Deposit Rates in Idaho and Montana", Review of Industrial Organization, Vol. 17, pp 427439. 
Unal, H. (1997), "Regulatory Misconceptions in Pricing Thrift Conversions: A Closer Look at the Appraisal Process", Journal of Finance Services Research, Vol. 11:3, pp. 239-254.

Wheelock, D. and P. Wilson (2000), "Why Do Banks Disappear? The Determinants of U.S. Bank Failures and Acquisitions", The Review of Economics and Statistics, Vol. 82:1, (Feb. 2000), pp. 127-138.

Wilcox, J. A. (2006), “Credit Union Conversions to Banks: Facts, Incentives, Issues and Reforms", Filene Research Institute. 


\section{Appendix A}

As mentioned in footnote (3), we also entertain an alternative assumption about the survival time data, where we still assume that the underlying survival time process is continuous. However, under the assumption that we actually observe the survival time data in discrete intervals, we employ lifetable methods in order to get estimates of the hazard, integrated hazard and survivor functions. The results from this alternative nonparametric estimation method are reported in figure 4. As before, the survival times depicted on the horizontal axes are quarters.

Upon examining the graphs below, it can be seen that the essence of the story remains the same. The peak(s) in the hazard function occurs at approximately the same location indicating an increase in the transition intensity at those survival times. The first peak is not as pronounced under the lifetable approach, although this estimate of the hazard function still retains its overall shape suggesting positive duration dependence. The points where the hazard function equals zero represents survival times where the hazard could not be estimated since there were no events which occurred during that interval of time. 


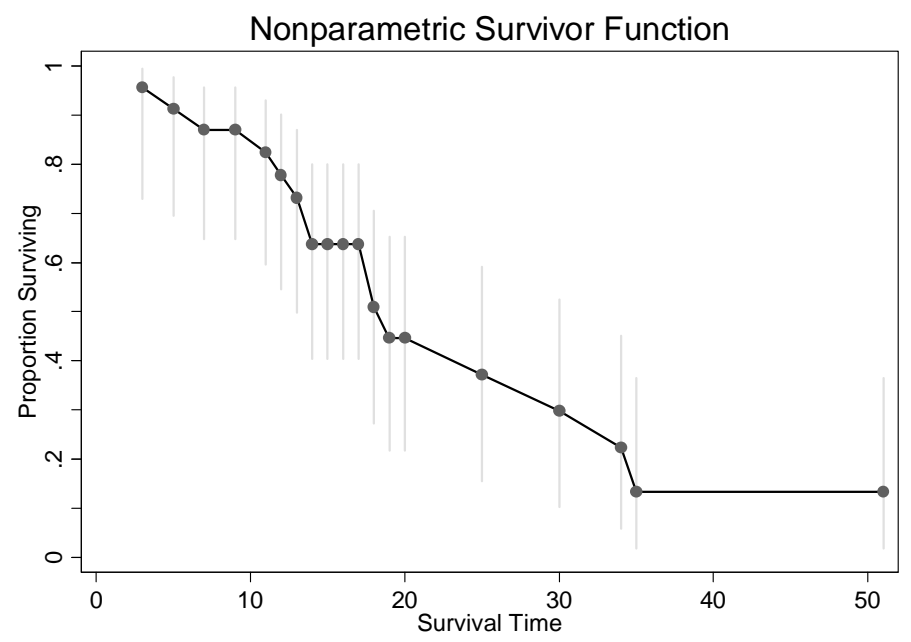

Figure 4(a)

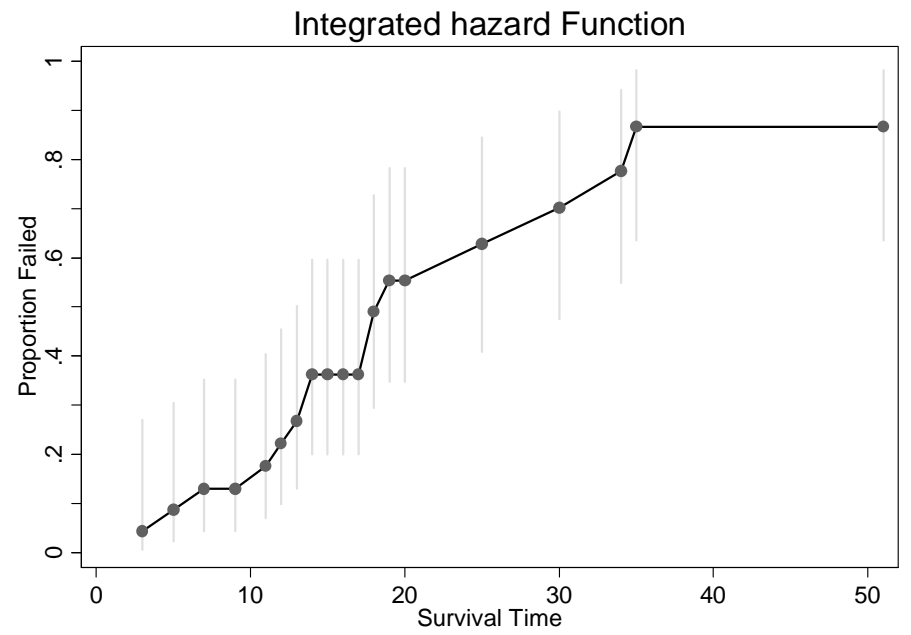

Figure 4(b)

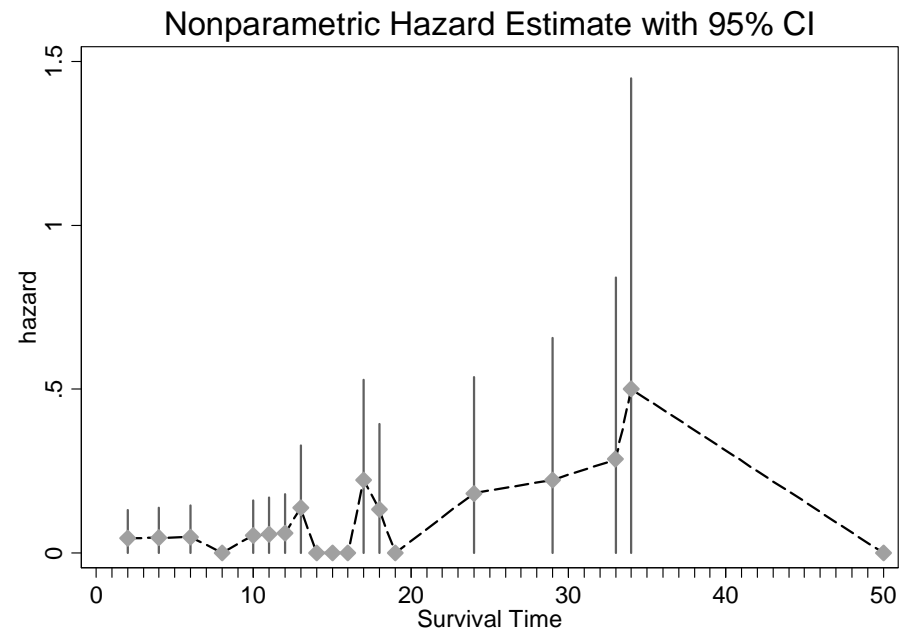

Figure 4(c)

Figure 4(a) - 4(c) : Survivor, Integrated Hazard and Interval Hazard functions estimated through lifetable methods 